\title{
A novel non-contact communication between human keratinocytes and T cells: Exosomes derived from keratinocytes support superantigen-induced proliferation of resting $T$ cells
}

\author{
XIAO-WEI CAI ${ }^{*}$, RONG ZHU* , LEI RAN, YI-QIAN LI, KE HUANG, \\ JING PENG, WEI HE, CHUN-LI ZHOU and RU-PENG WANG \\ Department of Dermatology and Rheumatology Immunology, Xinqiao Hospital, \\ Third Military Medical University, Chongqing 400000, P.R. China
}

Received January 11, 2017; Accepted July 27, 2017

DOI: $10.3892 / \mathrm{mmr} .2017 .7492$

\begin{abstract}
It is widely accepted that keratinocytes act as non-professional antigen-presenting cells and support superantigen-induced proliferation of resting $\mathrm{T}$ cells; however, it remains unknown whether keratinocytes function in situ with $\mathrm{T}$ cells via a non-contact mechanism. The current study used a transwell co-culture system and demonstrated, for the first time to the best of the authors' knowledge, that HaCaT cells (the human keratinocyte cell line) did induce $\mathrm{T}$ cell proliferation via indirect contact. The data further indicated that exosomes, small membrane vesicles that transfer antigens to recipient cells, are also involved in the superantigen-associated immunity of keratinocytes. The current study provided experimental evidence that $\mathrm{HaCaT}$-exosomes contained $\mathrm{MHC}$ I and II, and could interact with T cells. In addition, following interferon $\gamma$ stimulation, Staphylococcal aureus enterotoxin B-loaded HaCaT cells secreted exosomes to induce the proliferation of CD4+ and CD8+ T cells in vitro. This novel biological function of exosomes reveals a new mechanism of how keratinocytes participate in bacterial superantigen-induced immune responses.
\end{abstract}

\section{Introduction}

Staphylococcus aureus is an important type of bacteria, which has high colonization rate on the lesions of normal skin and in inflammatory skin diseases $(1,2)$. Infection and

Correspondence to: Dr Ru-Peng Wang, Department of Dermatology and Rheumatology Immunology, Xinqiao Hospital, Third Military Medical University, 108 Xinqiao Street, Chongqing 400000, P.R. China

E-mail:wrp71@163.com

*Contributed equally

Key words: exosomes, T cells, keratinocytes, Staphylococcal aureus enterotoxin B, Staphylococcus aureus colonization with $S$. aureus triggers the onset and aggravates the course of various inflammatory diseases, including atopic dermatitis $(1,3)$ and psoriasis (4). The secretion of $S$. aureus enterotoxin B (SEB), one type of staphylococcal superantigens, is a vital mechanism of how $S$. aureus acts. Keratinocytes, which account for $90 \%$ of epidermis, are also the main cells that SEB directly contact. Keratinocytes function as the barrier of the skin, and have an important role in skin immunity (5). For example, it has been proved that human keratinocytes were able to process endogenous and exogenous antigen and induced rapid effector function in antigen-specific memory $\mathrm{CD}^{+}$and CD8+ T cells (6). Previous researches also suggested that keratinocytes support superantigens-driven proliferation in resting $\mathrm{T}$ cells via cell-cell contacts in vitro $(7,8)$. The present study considered whether the direct contact is a prerequisite and foundation for human keratinocytes to activate $\mathrm{T}$ cells and whether there is a non-contact way to allow keratinocyte function in situ with T cells.

It is widely accepted that exosomes facilitate the direct extracellular transfer of proteins, lipids and RNA, in vitro and in vivo, which enables them to participate in intercellular communication without direct contact $(9,10)$. Exosomes are nano-size membrane vesicles (diameter, 30-100 nm) that form within late endocytic compartments, which are called multivesicular bodies, and are released to the extracellular medium by fusion of the plasma membrane (11). They contain a distinct set of proteins defined as exosomal markers, including tetraspanin family molecules (CD9, CD63, CD81), heat shock proteins (HSP) 70, HSP90, and components of the endosomal sorting complex required for transport machinery [e.g., programmed cell death 6 interacting protein and tumour susceptibility 101 (TSG101)] $(12,13)$. Furthermore, exosomes also typically carry a specific set of proteins associated with the cell type they originated from. For example, platelet-derived exosomes express the von Willebrand factor and CD41a, the exosomes from dendritic cells (DCs) express DC-specific maker CD11c, major histocompatibility complex (MHC) I and II, and costimulatory molecules [CD86 and intercellular adhesion molecule 1 (ICAM-1)] (14,15). Besides the protein, exosomes function similarly to original cells, such as, one proposed role of exosomes released by DCs is to spread antigens or 
MHC-peptide complexes to T cells or DCs causing immune reactions (16-18).

Therefore, due to the fact that keratinocytes directly presented SEB to resting $\mathrm{CD}^{+} \mathrm{T}$ cells in vitro, it was assumed that keratinocyte-derived exosomes, which could act as a 'truck' between keratinocytes and T cells, may also have the ability to function in superantigen-associated immunity. To address this question, $\mathrm{HaCaT}$ cells (keratinocyte cell line) were used to analyze the immune characteristics of exosomes derived from HaCaT cells. Experimental evidence was thus provided that $\mathrm{HaCaT}$ cells pretreated with SEB could induce the proliferation of T cells in a Transwell co-culture system, and the results demonstrated that $\mathrm{HaCaT}$ cells secrete exosomes and these exosomes carried MHC I and MHC II molecules when derived from $\mathrm{HaCaT}$ cells pretreated with interferon $\gamma$ (IFN $\gamma$ ). Furthermore, HaCaT-exosomes could interact with T cells, resulting in superantigen-induced proliferation of $\mathrm{CD}^{+}$ and $\mathrm{CD}^{+} \mathrm{T}$ cells in vitro.

\section{Materials and methods}

Reagents. SEB (Academy of Military Medical Science, Beijing, China), Leaf ${ }^{\mathrm{TM}}$ purified anti-human CD3, CD28 antibody (cat. nos. 300313 and 302913; BioLegend, Inc., San Diego, CA, USA), IFN $\gamma$ and IL-2 (PeproTech, Inc., Rocky Hill, NJ, USA) were used for cell stimulation. The following mouse antibodies were used for western blotting (all from Abcam, Cambridge, UK): Anti-human CD63, anti-human TSG101, anti-human calnexin, anti-human major histocompatibility complex, class I, A (HLA-A), anti-human major histocompatibility complex, class II, DR (HLA-DR), anti-human ICAM-1 and anti-human $\beta$-actin. Antibodies used for flow cytometry analysis were as follows (all from BioLegend, Inc.): Phycoerythrin (PE)-anti-human CD4, PE-cyanine7 anti-human CD8, allophycocyanin anti-human CD3 and PE-Cy7 anti-human CD69.

Cell sorting. Peripheral blood mononuclear cells (PBMCs) were isolated by means of Ficoll-Hypaque (Dakewei Biotech Co., Ltd, Shenzhen, China) density gradient centrifugation from heparinized venous blood obtained from healthy donors, as previously described (19). Human cells were obtained under protocols approved by the Medical Ethics Committee of Second Affiliated Hospital of Third Military Medical University, PLA (Chongqing, China). $\mathrm{CD}^{+} \mathrm{T}$ cells were sorted by positive selection with the IMagnet ${ }^{\mathrm{TM}}$ (BD IMag ${ }^{\mathrm{TM}}$; BD Biosciences, Franklin Lakes, NJ, USA) as described by the manufacturer. The purity of isolated $\mathrm{CD}^{+} \mathrm{CD}^{-} 9^{-} \mathrm{T}$ cells was $>95 \%$, detected by flow cytometer (Beckman Coulter, Inc., Brea, CA, USA) and analyzed by FlowJo software (version 7.6.1; FlowJo LLC, Ashland, OR, USA)

Cell culture and preconditioning. The HaCaT cells (Institute of Biochemistry and Cell Biology, CAS, Shanghai, China), and the sorted $\mathrm{CD}^{+} \mathrm{T}$ cells were cultured in RPMI medium (Hyclone; GE Healthcare Life Sciences, Logan, UT, USA) supplemented with $10 \%$ fetal bovine serum (FBS; Gibco; Thermo Fisher Scientific, Inc., Waltham, MA, USA) and $100 \mathrm{U} / \mathrm{ml}$ penicillin-streptomycin at $37^{\circ} \mathrm{C}$ in $5 \% \mathrm{CO}_{2}$. In the co-culture assay, HaCaT cells $\left(2 \times 10^{4}\right.$ cells/well $)$ were incubated with or without IFN $\gamma$ overnight $(300 \mathrm{U} / \mathrm{ml})$ and were then treated for another $4 \mathrm{~h}$ with or without the superantigens SEB (100 ng/ml). Finally, these cells were washed for three times to remove the solute SEB and IFN $\gamma$. For exosome collection, the treated $\mathrm{HaCaT}$ cells were resuspended in fresh culture medium with $10 \%$ exosomes-free FBS (prepared by overnight ultracentrifugation at 100,000 x g). After 48 h, cell culture supernatant was collected for exosome purification.

Cell proliferation assay. In the cell to cell experiment, Transwell chambers (8- $\mu \mathrm{m}$ pore membrane; EMD Millipore, Billerica, MA, USA) were used to determine the capacity of SEB-loaded HaCaT cells to promote $\mathrm{T}$ cell proliferation under non-contact conditions. Purified $\mathrm{CD}^{+} \mathrm{T}$ cells were labeled with $5 \mu \mathrm{M}$ carboxyfluorescein succinimidyl ester (CFSE; Invitrogen; Thermo Fisher Scientific, Inc.) and then were seeded on 24-well cell culture cluster plates at a concentration of $4 \times 10^{5}$ cells/well in volumes of $500 \mu \mathrm{l}$. SEB-loaded HaCaT cells $(+/$-IFN $\gamma)$ were seeded on the Transwell chambers at a concentration of $2 \times 10^{4}$ cells/well in volumes of $200 \mu \mathrm{l}$. In the cell proliferation experiment of exosomes, the assays were performed in 96-well round-bottom plates in complete RPMI modified medium. The CFSE-labeled T cells ( $2 \times 10^{5} /$ well) in a total volume of $200 \mu \mathrm{l}$ were stimulated with HaCaT-exosomes $(+/-\mathrm{SEB},+/$-IFN $\gamma)$. As a positive control to detect whether the CFSE-labeled $\mathrm{T}$ cells were able to proliferate, $\mathrm{CD}^{+} \mathrm{T}$ cells were cultured in plates precoated with $4 \mu \mathrm{g} / \mathrm{ml}$ anti-CD3 and $2 \mu \mathrm{g} / \mathrm{ml}$ anti-CD28 antibodies and stimulated with IL-2 (30 IU/ml), as previously described (20). After 5 days, T cells were staining with $5 \mu \mathrm{g} / \mathrm{ml}$ anti-human CD3, CD4 and CD8 antibody. Finally, the stained cells were analyzed using a flow cytometer (Beckman Coulter, Inc., Brea, CA, USA).

Exosomes purification. The cell culture supernatants were centrifuged at $300 \mathrm{x} \mathrm{g}$ for $10 \mathrm{~min}, 2,000 \mathrm{xg}$ for $10 \mathrm{~min}$ at $4^{\circ} \mathrm{C}$, and filtered through a $0.22 \mu \mathrm{m}$ sterilizing filter (Corning Incorporated, Corning, NY, USA). Exosomes were pelleted by ultracentrifugation at $100,000 \mathrm{x}$ g for $70 \mathrm{~min}$ at $4^{\circ} \mathrm{C}$ and then were resuspended in PBS. Protein level was quantified by bicinchoninic acid protein assay (Beyotime Institute of Biotechnology, Haimen, China).

Transmission electron microscopy. To analyze the structure of exosomes derived from HaCaT cells (+/-IFN $\gamma$ ), a $10 \mu \mathrm{l}$ suspension of exosomes (+/-IFN $\gamma$ ) was loaded onto Formvar carbon-coated 200 mesh copper grids for $10 \mathrm{~min}$ at room temperature. Excessive fluid was slightly drained with filter paper and then the adsorbed exosomes were negatively stained with $1 \%$ phosphotungstic acid for $5 \mathrm{~min}$. Finally, the air-dried grids were observed using a transmission electron microscope (JEM-1400 PLUS, JEOL, Ltd., Tokyo, Japan) operating at $100 \mathrm{kV}$.

Fluorescence confocal microscopy. The PKH67 (Sigma-Aldrich; Merck KGaA, Darmstadt, Germany) was used to label exosomes according to the manufacturer's protocols. Briefly, exosomes $(\sim 100 \mu \mathrm{g}$ in $100 \mu \mathrm{l})$ were resuspended in $0.5 \mathrm{ml}$ of diluent $\mathrm{C}$ (Sigma-Aldrich; Merck KGaA) and then mixed with PKH67 diluted in diluent $\mathrm{C}$ for a final concentration of $2 \times 10^{-6} \mathrm{M}$ PKH67. The exosomes dye suspension was incubated for $5 \mathrm{~min}$ at room temperature. Excessive 

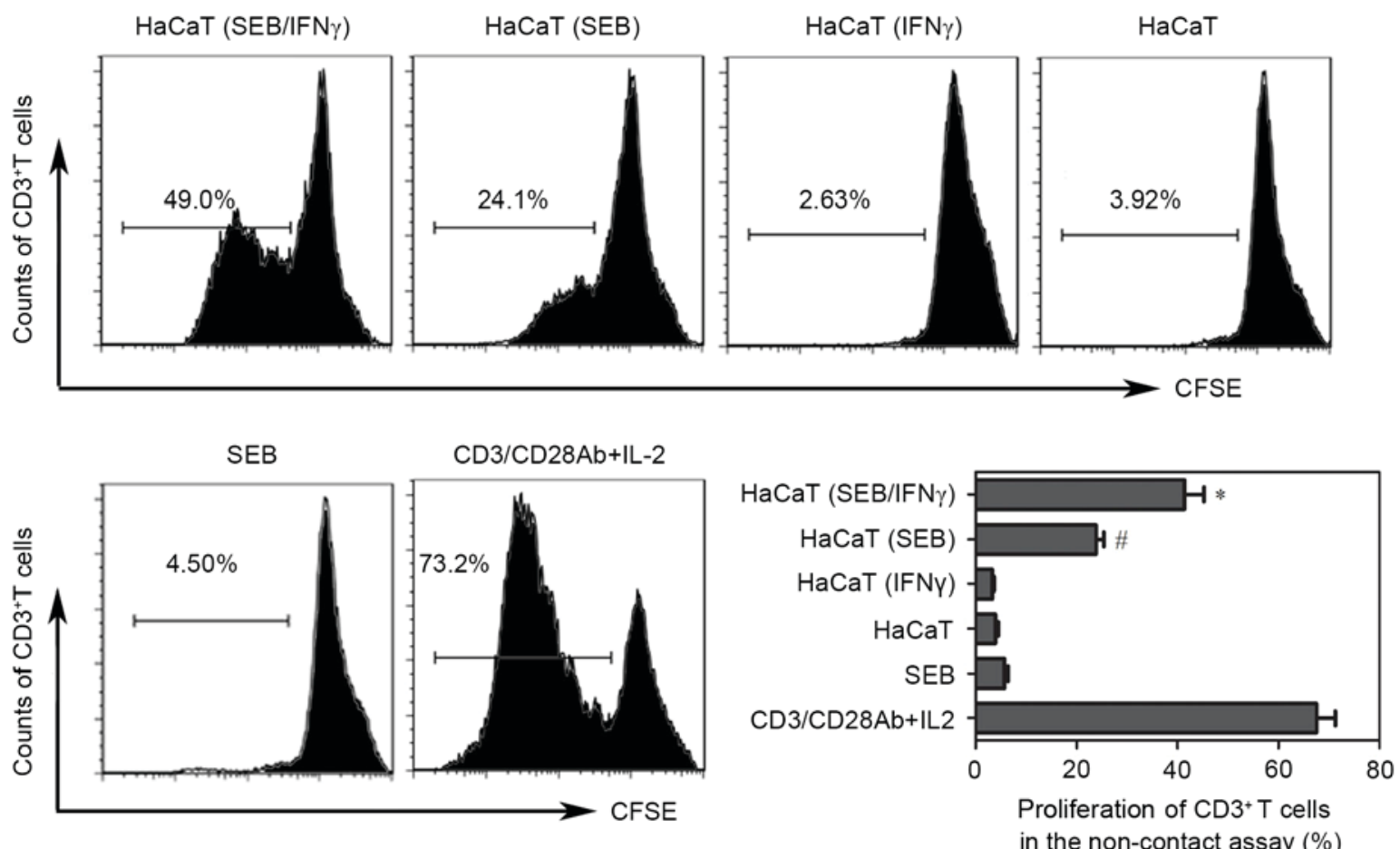

Figure 1. SEB-loaded HaCaT cells induce the proliferation of resting $\mathrm{CD}^{+} \mathrm{T}$ cells in a non-contact assay. HaCaT cells and solute SEB (100 ng/ml) only served as negative control. Anti-human CD3/CD28 antibodies and IL-2 were used to stimulate T cells as a positive control. Values are presented as the mean \pm standard, $\mathrm{n}=3 .{ }^{*} \mathrm{P}<0.05$ vs. HaCaT (SEB) and the negative control groups. ${ }^{*} \mathrm{P}<0.05$ vs. HaCaT (SEB/IFN $\gamma$ ) and the negative control groups. SEB, Staphylococcus aureus enterotoxin B; IFN $\gamma$, interferon $\gamma$; IL-2, interleukin-2; CFSE, carboxyfluorescein succinimidyl ester.

dye from the labeled exosomes was neutralized with $1 \mathrm{ml}$ 5\% bovine serum albumin. Finally, the supernatant were removed by centrifugation $\left(100,000 \mathrm{x}\right.$ g for $70 \mathrm{~min}$ at $\left.4^{\circ} \mathrm{C}\right)$ and PKH67-labeled exosomes were resuspended in $50 \mu \mathrm{l}$ PBS.

PKH67-labeled exosomes derived from $\mathrm{HaCaT}$ cells were co-incubated with $\mathrm{CD}^{+} \mathrm{T}$ cells for $4 \mathrm{~h}$ at $37^{\circ} \mathrm{C}$. The slides of cells were then washed in PBS three times followed by fixation in $4 \%$ paraformaldehyde for $15 \mathrm{~min}$ at room temperature. The cellular nuclei were stained with $0.5 \mu \mathrm{g} / \mathrm{ml}$ DAPI. Imaging was performed using a fluorescence confocal microscope. Images were analyzed with Leica Application Suite Advanced Fluorescence software (version 2.3.0, build 5131; Leica Microsystems, Inc., Buffalo Grove, IL, USA).

SDS-PAGE and western blot analysis. HaCaT cells or exosomes (+/-IFN $\gamma$ ) were lysed in radioimmunoprecipitation lysis buffer $(50 \mathrm{mM}$ Tris, $\mathrm{pH} 7.4,150 \mathrm{mM} \mathrm{NaCl}, 1 \%$ Triton X-100, $1 \%$ sodium deoxycholate, $0.1 \%$ SDS, sodium orthovanadate, sodium fluoride, EDTA, leupeptin and $1 \mathrm{mM}$ PMSF). Protein of cells and exosomes was quantified by bicinchoninic acid protein assay (Beyotime Institute of Biotechnology, Haimen, China). Equal amounts of protein $(\sim 20 \mu \mathrm{g})$ were subjected to $10 \%$ SDS-PAGE, transferred to a polyvinylidene difluoride membrane (PVDF; $0.45 \mu \mathrm{m}$; EMD Millipore). PVDF membranes were blocked with 5\% non-fat milk for $2 \mathrm{~h}$ at room temperature, and then incubated with the diluted anti-CD63, anti-TSG101, anti-calnexin antibody, anti-HLA-A, anti-HLA-DR, anti-ICAM- 1 , anti- $\beta$-actin solution $(1: 1,000)$ overnight at $4^{\circ} \mathrm{C}$. Washed membranes were probed with a horseradish peroxidase-conjugated secondary antibody (cat. no. A0216; Beyotime Institute of Biotechnology, Haimen, China) at a 1:1,000 dilution for $2 \mathrm{~h}$. The results were visualized by chemiluminescence substrate (Pierce; Thermo Fisher Scientific, Inc.). Densitometry was performed using ImageJ software (version 1.45; National Institutes of Health, Bethesda, MD, USA).

Statistical analysis. When appropriate, data are presented as the mean \pm standard deviation. Multiple comparisons were made using one-way analysis of variance followed by the Bonferroni post hoc test. $\mathrm{P}<0.05$ was considered to indicate a statistically significant difference.

\section{Results}

SEB-loaded HaCaT cells (+/-IFN $\gamma$ ) induce Tcell proliferation without direct contact. To detect the ability of HaCaT cells in presenting SEB to resting $\mathrm{T}$ cells under non-contact conditions, indirect co-culture experiments were performed using the Transwell system. The results demonstrated that SEB-loaded HaCaT cells induced the proliferation of resting T cells (Fig. 1). Previous studies have suggested that under inflammatory conditions, such as when stimulated by IFN $\gamma$, keratinocytes express MHC II, ICAM-1 and increased levels of MHC I to make these cells compatible with competent presentation of antigens to $\mathrm{T}$ cells (6). Therefore, $\mathrm{T}$ cell proliferation driven by SEB-loaded HaCaT cells pretreated with IFN $\gamma$ was also investigated. The data indicated that the proliferation of $\mathrm{T}$ cells was increase compared with the untreated condition in this indirect co-culture system. 
A

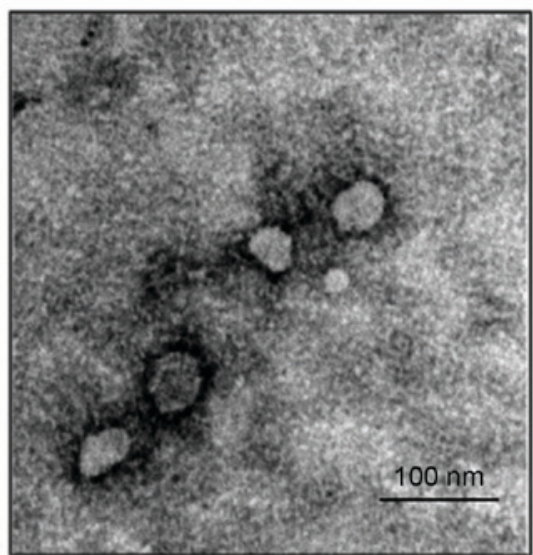

C

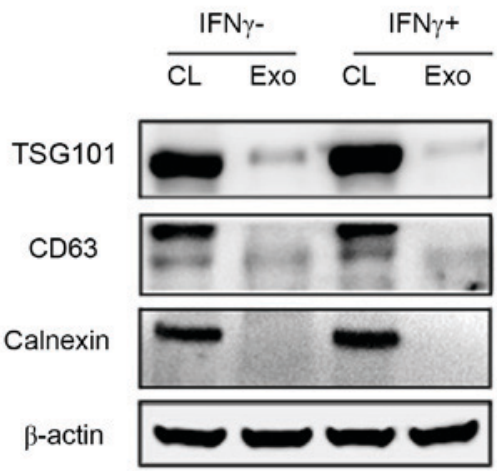

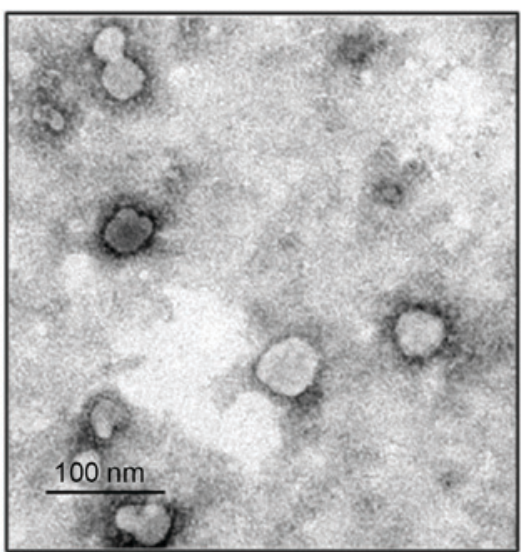

D

$$
\frac{\mathrm{IFN} \gamma-}{\mathrm{CL} \quad \mathrm{ExO}} \quad \frac{\mathrm{IFN} \gamma^{+}}{\mathrm{CL} \quad \mathrm{ExO}}
$$

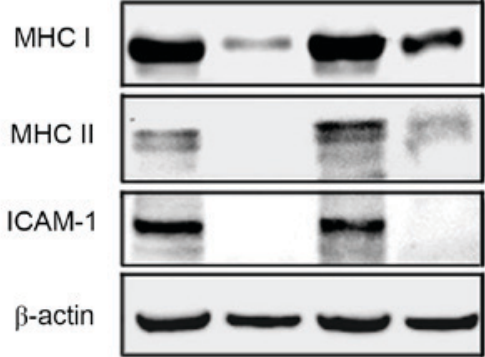

Figure 2. Analysis of the features of exosomes secreted by HaCaT cells. (A) Exosomes derived from HaCaT cells (IFN $\gamma$-) and (B) exosomes derived from $\mathrm{HaCaT}$ cells (IFN $\gamma+$ ) with characterizations of HaCaT-released exosomes observed by transmission electron microscope (x120,000). Two types of exosomes from $\mathrm{HaCaT}$ were roughly identical, ranging from 30 to $100 \mathrm{~nm}$. (C) Western blotting were performed using vesicles protein to validate exosomal markers CD63, TSG101 and negative protein calnexin. (D) Western blotting was performed for immune molecules MHC I, MHC II molecules and ICAM-1 in the HaCaT-exosomes. CL, cell lysate; Exo, exosomes. IFN $\gamma$, interferon $\gamma$; CL, cell lysate; Exo, exosomes; TSG101, tumour susceptibility 101; MHC, major histocompatibility complex; ICAM-1, intracellular adhesion molecule-1.

HaCaT cells produce typical exosomes with or without IFN $\gamma$. Exosomes were purified from HaCaT culture supernatants by ultracentrifugation, and identified with electron microscopy and western blotting analysis. The data demonstrated that exosomes derived from the HaCaT cells stimulated with or without IFN $\gamma$ both had a typical exosomal round shape with a diameter between 30 and $100 \mathrm{~nm}$ (Fig. 2A and B). Additionally, these exosomes contained exosome marker proteins such as CD63 and TSG101. The exosomes were negative for calnexin, which is specifically expressed and located in endoplasmic reticulum (Fig. 2C and D).

HaCaT cell exosomes express MHC I and induced MHC II molecules. To assess the ability of HaCaT-exosomes to present peptides, whether HaCaT-exosomes contained MHC I and MHC II molecules with or without stimulation of IFN $\gamma$ was determined. The data demonstrated that HaCaT-exosomes expressed low levels of MHC I but no MHC II molecules (Fig. 2D), suggesting that HaCaT-exosomes have the potential function of presenting peptide to $\mathrm{CD}^{+} \mathrm{T}$ cells under resting condition. When $\mathrm{HaCaT}$ cells were pretreated by IFN $\gamma$, HaCaT-exosomes expressed low level of MHC II molecules and the MHC I was further upregulated (Fig. 2D).

In addition, previous studies have suggested an important role of ICAM-1 and the leukocyte function-associated
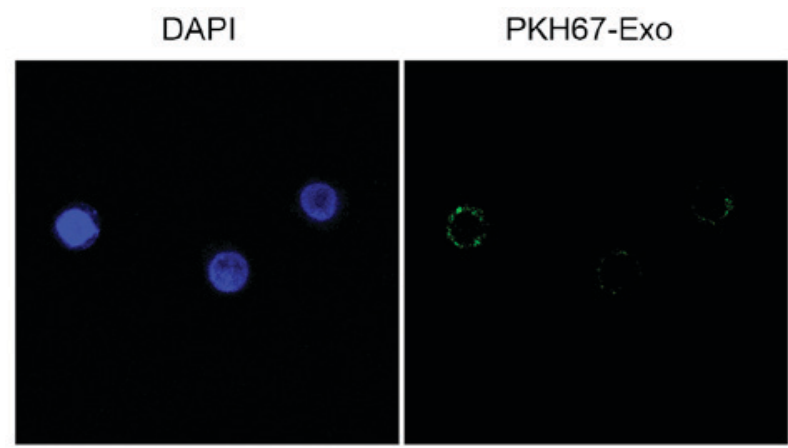

Morphology

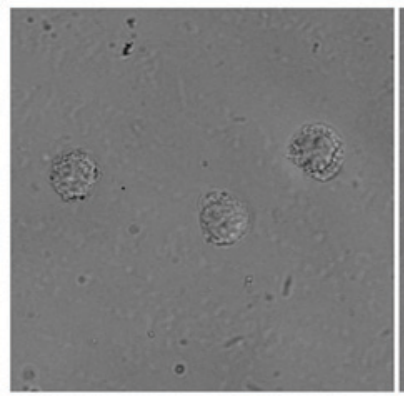

Merged

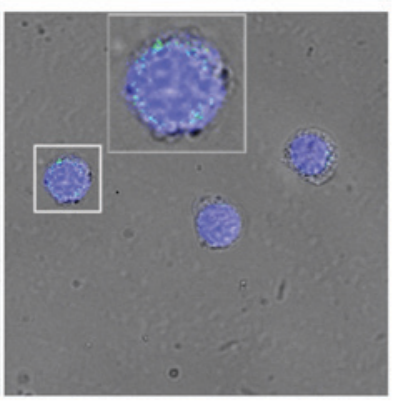

Figure 3. Interaction between HaCaT-derived exosomes and $\mathrm{T}$ cells was observed by confocal fluorescence microscopy. T cells were incubated with HaCaT-derived exosomes for $4 \mathrm{~h}$ at $37^{\circ} \mathrm{C}$. Green, PKH67 fluorescence; Blue, DAPI stained nuclei. 

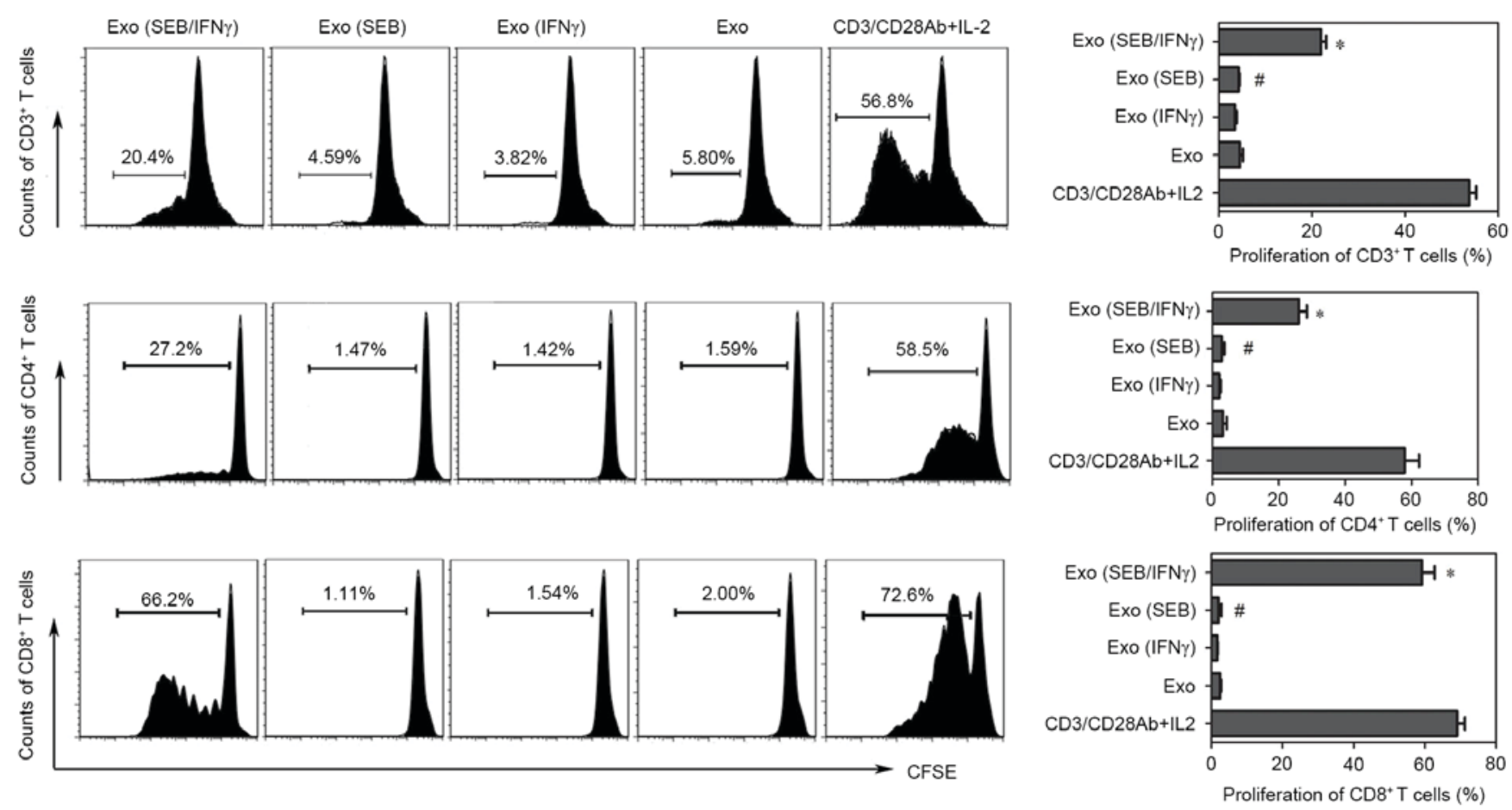

Figure 4. Exosomes released from SEB-loaded HaCaT cells ( $+\mathrm{IFN} \gamma)$ induce the proliferation of resting $\mathrm{CD}^{+}, \mathrm{CD}^{+}, \mathrm{CD}^{+} \mathrm{T}$ cells. Exosomes derived from HaCaT cells (+/-IFN $\gamma$ ) served as a negative control. Anti-human CD3/CD28 antibodies and IL-2 were used together to stimulate T cells as a positive control. The proliferation of $\mathrm{CD}^{+} \mathrm{T}$ cells was measured by flow cytometry. The $\mathrm{CD} 4^{+}$and $\mathrm{CD} 8^{+} \mathrm{T}$ cells were gated in the $\mathrm{CD} 3^{+} \mathrm{T}$ cells and their proliferation were detected by flow cytometry. Values are presented as the mean \pm standard deviation. $n=3$. ${ }^{*}<<0.05$ vs. Exo (SEB) and the negative control groups. ${ }^{\text {" }} \mathrm{P}<0.05$ vs. Exo (SEB/IFN $\gamma$ ) and the negative control groups. Exo, exosomes; SEB, Staphylococcus aureus enterotoxin B; IFN $\gamma$, interferon $\gamma$; Ab, antibody; IL-2, interleukin-2; CFSE, carboxyfluorescein succinimidyl ester.

antigen-1 (LFA-1) interaction in presentation function of keratinocytes for superantigens (7) and in $\mathrm{T}$ cell adherence to keratinocytes (21). The exosomes from HaCaT cells did not express ICAM-1 molecules under steady state or inflammatory conditions (+/-IFN $\gamma$; Fig. 2D).

HaCaT-derived exosomes interact with T cells. To explore whether the HaCaT-exosomes could interact with $\mathrm{T}$ cells, confocal fluorescence microscopy was used to track the PKH67-labeled HaCaT-exosomes in T cells. After incubation of PKH67 labeled exosomes with the T cells for $4 \mathrm{~h}$ at $37^{\circ} \mathrm{C}$, we observed an obvious green fluorescence in the $\mathrm{T}$ cells indicating an active exosomes interaction with $\mathrm{T}$ cells (Fig. 3). This result suggests a potential role of exosomes in a short-range interaction between HaCaT cells and $\mathrm{T}$ cells.

SEB-loaded-exosomes from HaCaT cells can induce the proliferation of $\mathrm{CD}^{+}$and $C D 8^{+} T$ cells. In the proliferation experiments, the results demonstrated that exosomes from SEB loaded HaCaT cells could induce the proliferation of $\mathrm{CD}^{+}$ $\mathrm{T}$ cells when the HaCaT cells were pre-stimulated with IFN $\gamma$. It was previously reported that Staphylococcus aureus could induce notable proliferation of $\mathrm{CD}^{+}$and $\mathrm{CD}^{+} \mathrm{T}$ cells, which were two main subpopulations of $\mathrm{CD}^{+} \mathrm{T}$ cells (22). Therefore, the $\mathrm{CD}^{+}{ }^{+}$and $\mathrm{CD} 8^{+} \mathrm{T}$ cells in the $\mathrm{CD} 3^{+} \mathrm{T}$ cells were gated to detect the proliferations. Correspondingly, the $\mathrm{CD}^{+}{ }^{+} \mathrm{CD} 4^{+}$and $\mathrm{CD}^{+}{ }^{+} \mathrm{CD} 8^{+} \mathrm{T}$ cells proliferated following induction by exosomes from SEB-HaCaT cells treated with IFN $\gamma$ (Fig. 4).

\section{Discussion}

Keratinocytes are the first and major point of contact with many potential antigens; therefore, it is important to understand how keratinocyte present antigens to T cells both for disease pathogenesis and also for potential delivery of vaccination antigens via the skin (6). Previous studies demonstrated that exosomes have an important role in modulation of immune responses. However, data about potential immunomodulatory functions of human keratinocyte exosomes are scant. In this study, to the best of our knowledge, it was demonstrated for the first time that $\mathrm{HaCaT}$ cells (human keratinocyte cell line) induce $\mathrm{T}$ cell proliferation in a non-contact manner. Furthermore, it was demonstrated that $\mathrm{HaCaT}$ cells release the nano-size exosomes to react with the $\mathrm{T}$ cells. This novel biological function of exosomes reveals a new short-range mechanism between keratinocytes and $\mathrm{T}$ cells in skin immunity to superantigens.

Keratinocytes are thought to display features of antigen-presenting cells (APCs) (5) and IFN $\gamma$ is reported to upregulate MHC class II expression on keratinocytes, thus enhancing their antigen presenting capacities. In the present study, SEB-loaded HaCaT cells (IFN $\gamma$ treated and untreated) induced the proliferation of $\mathrm{CD}^{+} \mathrm{T}$ cells under indirect co-culture conditions. Keratinocytes are able to transfer immune information to T cells via soluble factors; for example, keratinocytes produce a large range of cytokines, including pro-inflammatory cytokines and chemokines (23). However, none of these known factors directly induce the proliferation of resting $\mathrm{T}$ cells, thus the role of exosomes in the SEB-associated immunity was investigated. 
In the current study, immune potential of HaCaT-exosomes was investigated. A previous study have suggested that keratinocytes constitutively expressed MHC class I molecules and had induced expression of MHC class II molecules under inflammatory conditions in vivo (24) or following treatment with IFN $\gamma$ in vitro (6), thus we investigated the level of MHC class I and II in HaCaT-exosomes with or without IFN $\gamma$ stimulation. The result indicated that compared with the $\mathrm{HaCaT}$ cells, exosomes contained lower MHC I levels but did not contain MHC II. The expression of MHC I increased and MHC II was induced at a low level in the exosomes derived from the HaCaT cells following IFN $\gamma$ stimulation. The presence of MHC I and MHC II molecules implies the potential capacities of HaCaT-exosomes in antigen-presentation to $\mathrm{CD}^{+}$and $\mathrm{CD}^{+} \mathrm{T}$ cells. Additionally, the expression of MHC I and II in exosomes derived from $\mathrm{HaCaT}$ cells were different from the results detected in murine keratinocytes, where murine keratinocytes-derived exosomes did not express MHC II, irrespective of IFN $\gamma$ stimulation (25). These divergent results may be due to the species difference between humans and mice; unlike human keratinocytes, not all murine keratinocytes express MHC II in vitro (26).

Keratinocyte-derived exosomes were observed to be internalized by DCs (25) and bone marrow-derived DCs (27) in vitro. In the current study, HaCaT-derived exosomes could interact with T cells. However, vesicles $<200 \mathrm{~nm}$ in diameter cannot be detected by confocal microscopy techniques, and detailed visualization of exosomes can only be observed by electron microscopy (28). Thus, how individual exosomes interact with target cells remains unknown. A previous study proposed this process to involve binding at the cell surface via specific receptors, and then internalizing through the endocytic pathway of the target cell, and/or by direct fusion with the membrane (28). For example, previous study indicated that $\mathrm{T}$ cells recruited exosomes secreted by DCs depending on the interaction of ICAM-1/LFA-1 (29). Unfortunately, in the current study, no ICAM-1 was detected in HaCaT-exosomes, so factors functioning in the interaction between $\mathrm{HaCaT}$-exosomes and $\mathrm{T}$ cells are unknown and require further research.

HaCaT-exosomes did induce SEB-associated proliferation of resting $\mathrm{CD}^{+}$and $\mathrm{CD}^{+} \mathrm{T}$ cells in the experiments of the current study, though it is unclear which factors mediated the interaction between HaCaT-exosomes and T cells. The present study demonstrated that exosomes induce the proliferation of $\mathrm{CD}^{+}$and $\mathrm{CD}^{+} \mathrm{T}$ cells when derived from IFN $\gamma$-treated $\mathrm{HaCaT}$ cells rather than untreated ones. Superantigens are a type of special antigen. They bind directly to MHC II molecules on APCs instead of intracellular processing into the APCs, and simultaneously they bind to the variable region of the $\mathrm{V} \beta$ chain of a $\mathrm{T}$ cell receptor (30). Due to the special binding mechanism and various $\mathrm{V} \beta$ isotypes, superantigens bypass the normal mechanisms of conventional MHC-restricted antigen presentation and the number of $\mathrm{T}$ cells activated by superantigens exceeds that of a conventional antigen. For example, the S. aureus 161:2 (carrying the genes for staphylococcal enterotoxin $\mathrm{A}$ and $\mathrm{H}$ ) could activate the human mucosal-associated invariant T cells, $\gamma \delta \mathrm{T}$ cells, and conventional $\mathrm{CD}^{+}$and $\mathrm{CD} 8^{+}$ $\mathrm{T}$ cells in vitro (22). Given that superantigens require the MHC II molecules on antigen-presenting cells as the binding site, stimulation of IFN $\gamma$ increased the expression of MHC II in exosomes, thus potentially accounting for the increase of $\mathrm{T}$ cells proliferation supporting by $\mathrm{HaCaT}$-exosomes. In addition, as in bone marrow dendritic cells (BM-DCs), exosomes are more efficient to activate ovalbumin (OVA)-specific MHC class I-restricted $\mathrm{T}$ cell hybridomas, when derived from OVA peptide loaded mature BM-DCs rather than those from immature BM-DCs (31). Keratinocytes are thought to be non-professional APCs, so their exosomes are much more similar to those of the immature DC than those of mature ones. The current study and these previous finding suggest an immunomodulatory role of exosomes depending on the state of the corresponding origin cell. Furthermore, the presence of staphylococcal colonization and staphylococcal superantigens is associated with various skin diseases (30). For example, superantigens-mediated $\mathrm{T}$ cell activation may initiate and propagate psoriasis $(32,33)$. S. aureus, $60 \%$ producing superantigens (most often SEB), is present in $>50 \%$ of patients with psoriasis and the severity of psoriasis is significantly correlated to enterotoxin production of S. aureus strains (34). As keratinocytes are the most abundant cell type in the skin, they are also the main cells with which $S$. aureus contact. Therefore, it is reasonable to presume that in skin inflammatory diseases superantigens are produced by $S$. aureus and then keratinocytes release exosomes, which may worsen the inflammation by inducing superantigen-associated proliferation of $\mathrm{T}$ cells. If the hypothesis is viable that keratinocytes-exosomes are capable of playing a similar role in the SEB or other superantigen-associated inflammatory disease in vivo, the exosomes inhibitor could decrease immune responses, thus offering a potential future therapeutic approach.

In conclusion, superantigens produced by microbes may cause a potent $\mathrm{T}$-cell activation and proliferation in their target tissues, which maintains chronic inflammation if not appropriately treated. The current study verified a novel non-contact, but supportive function between keratinocyte and targeted $\mathrm{T}$ cells in the SEB-associated cutaneous immunity. Furthermore, the results unveil a novel role of keratinocyte-derived exosomes in superantigen-associated diseases, and indicates that IFN $\gamma$ stimulation is an important factor in influencing the immunity of keratinocyte-exosomes. However, which factors these effects are mediated by and what the possible reaction could be in vivo remains unclear.

\section{Acknowledgements}

The current study was supported by the National Natural Science Foundation of China (grant no. 81271767).

\section{References}

1. Abeck D and Mempel M: Staphylococcus aureus colonization in atopic dermatitis and its therapeutic implications. Br J Dermatol 139 (Suppl 53): S13-S16, 1998.

2. Miko BA, Uhlemann AC, Gelman A, Lee CJ, Hafer CA, Sullivan SB, Shi Q, Miller M, Zenilman J and Lowy FD: High prevalence of colonization with Staphylococcus aureus clone USA300 at multiple body sites among sexually transmitted disease clinic patients: An unrecognized reservoir. Microbes Infec 14: 1040-1043, 2012.

3. Mernelius S, Carlsson E, Henricson J, Löfgren S, Lindgren PE, Ehricht R, Monecke S, Matussek A and Anderson CD: Staphylococcus aureus colonization related to severity of hand eczema. Eur J Clin Microbiol Infect Dis 35: 1355-1361, 2016. 
4. Elfatoiki FZ, El Azhari M,El Kettani A, Serhier Z, Othmani MB, Timinouni M, Benchikhi H, Chiheb S and Fellah H: Psoriasis and Staphylococcus aureus skin colonization in Moroccan patients. Pan Afr Med J 23: 33, 2016.

5. Nestle FO, Di Meglio P, Qin JZ and Nickoloff BJ: Skin immune sentinels in health and disease. Nat Rev Immunol 9: 679-691, 2009.

6. Black AP, Ardern-Jones MR, Kasprowicz V, Bowness P, Jones L Bailey AS and Ogg GS: Human keratinocyte induction of rapid effector function in antigen-specific memory CD4+ and CD8+ T cells. Eur J Immunol 37: 1485-1493, 2007.

7. Nickoloff BJ, Mitra RS, Green J, Zheng XG, Shimizu Y, Thompson C and Turka LA: Accessory cell function of keratinocytes for superantigens. Dependence on lymphocyte function-associated antigen-1/intercellular adhesion molecule-1 interaction. J Immunol 150: 2148-2159, 1993.

8. Li LB, Goleva E, Hall CF, Ou LS and Leung DY: Superantigeninduced corticosteroid resistance of human T cells occurs through activation of the mitogen-activated protein kinase kinase/extracellular signal-regulated kinase (MEK-ERK) pathway. J Allergy Clin Immunol 114: 1059-1069, 2004.

9. Simons M and Raposo G: Exosomes-vesicular carriers for intercellular communication. Curr Opin Cell Biol 21: 575-581, 2009.

10. Mathivanan S, Ji H and Simpson RJ: Exosomes: Extracellular organelles important in intercellular communication. J Proteomics 73: 1907-1920, 2010.

11. Théry C, Amigorena S, Raposo G and Clayton A: Isolation and characterization of exosomes from cell culture supernatants and biological fluids. Curr Protoc Cell Biol Chapter 3: Unit 3.22, 2006.

12. Théry C, Ostrowski M and Segura E: Membrane vesicles as conveyors of immune responses. Nat Rev Immunol 9: 581-593, 2009

13. Ohno S, Ishikawa A and Kuroda M: Roles of exosomes and microvesicles in disease pathogenesis. Adv Drug Deliv Rev 65: 398-401, 2013

14. Chaput N, Flament C, Viaud S, Taieb J, Roux S, Spatz A André F, LePecq JB, Boussac M, Garin J, et al: Dendritic cell derived-exosomes: biology and clinical implementations. J Leukoc Biol 80: 471-478, 2006.

15. Johansson SM, Admyre C, Scheynius A and Gabrielsson S: Different types of in vitro generated human monocyte-derived dendritic cells release exosomes with distinct phenotypes. Immunology 123: 491-499, 2008.

16. Bobrie A, Colombo M, Raposo G and Théry C: Exosome secretion: Molecular mechanisms and roles in immune responses. Traffic 12: 1659-1668, 2011.

17. Montecalvo A, Shufesky WJ, Stolz DB, Sullivan MG, Wang Z, Divito SJ, Papworth GD, Watkins SC, Robbins PD, Larregina AT and Morelli AE: Exosomes as a short-range mechanism to spread alloantigen between dendritic cells during $\mathrm{T}$ cell allorecognition. J Immunol 180: 3081-3090, 2008.

18. André F, Chaput N, Schartz NE, Flament C, Aubert N, Bernard J, Lemonnier F, Raposo G, Escudier B, Hsu DH, et al: Exosomes as potent cell-free peptide-based vaccine. I. Dendritic cell-derived exosomes transfer functional MHC class I/peptide complexes to dendritic cells. J Immunol 172: 2126-2136, 2004

19. Mallone R,Mannering SI,Brooks-Worrell BM,Durinovic-BellóI, Cilio CM, Wong FS and Schloot NC; T-CellWorkshop Committee, Immunology of Diabetes Society: Isolation and preservation of peripheral blood mononuclear cells for analysis of islet antigen-reactive T cell responses: Position statement of the T-cell workshop committee of the immunology of diabetes society. Clin Exp Immunol 163: 33-49, 2011.
20. Wang TT, Zhao YL, Peng LS, Chen N, Chen W, Lv YP, Mao FY, Zhang JY, Cheng P, Teng YS, et al: Tumour-activated neutrophils in gastric cancer foster immune suppression and disease progression through GM-CSF-PD-L1 pathway. Gut: Mar 8, 2017 (Epub ahead of print).

21. Dustin ML, Singer KH, Tuck DT and Springer TA: Adhesion of $\mathrm{T}$ lymphoblasts to epidermal keratinocytes is regulated by interferon gamma and is mediated by intercellular adhesion molecule 1 (ICAM-1). J Exp Med 167: 1323-1340, 1988.

22. Johansson MA, Björkander S, MataForsberg M, Qazi KR, Salvany Celades M, Bittmann J, Eberl M and Sverremark-Ekström E: Probiotic lactobacilli modulate Staphylococcus aureus-induced activation of conventional and unconventional T cells and NK cells. Front Immunol 7: 273, 2016.

23. Gröne A: Keratinocytes and cytokines. Vet Immunol Immunopathol 88: 1-12, 2002.

24. Nickoloff BJ and Turka LA: Immunological functions of non-professional antigen-presenting cells: New insights from studies of T-cell interactions with keratinocytes. Immunol Today 15: 464-469, 1994.

25. Kotzerke K, Mempel M, Aung T, Wulf GG, Urlaub H, Wenzel D, Schön MP and Braun A: Immunostimulatory activity of murine keratinocyte-derived exosomes. Exp Dermatol 22: 650-655, 2013.

26. Gaspari AA and Katz SI: Induction and functional characterization of class II MHC (Ia) antigens on murine keratinocytes. J Immunol 140: 2956-2963, 1988.

27. Morelli AE, Larregina AT, Shufesky WJ, Sullivan ML, Stolz DB, Papworth GD, Zahorchak AF, Logar AJ, Wang Z, Watkins SC, et al: Endocytosis, intracellular sorting, and processing of exosomes by dendritic cells. Blood 104: 3257-3266, 2004.

28. Théry C: Exosomes: Secreted vesicles and intercellular communications. F1000 Biol Rep 3: 15, 2011.

29. Nolte-'t Hoen EN, Buschow SI, Anderton SM, Stoorvogel W and Wauben MH: Activated T cells recruit exosomes secreted by dendritic cells via LFA-1. Blood 113: 1977-1981, 2009.

30. Macias ES, Pereira FA, Rietkerk W and Safai B: Superantigens in dermatology. J Am Acad Dermatol 64: 455-474, 2011.

31. Utsugi-Kobukai S, Fujimaki H, Hotta C, Nakazawa M and Minami M: MHC class I-mediated exogenous antigen presentation by exosomes secreted from immature and mature bone marrow derived dendritic cells. Immunol Lett 89: 125-131, 2003.

32. Zhao G, Feng X, Na A, Yongqiang J, Cai Q, Kong J and Ma H: Acute guttate psoriasis patients have positive streptococcus hemolyticus throat cultures and elevated antistreptococcal M6 protein titers. J Dermatol 32: 91-96, 2005.

33. Leung DY, Travers JB, Giorno R, Norris DA, Skinner R, Aelion J, Kazemi LV, Kim MH, Trumble AE, Kotb M, et al: Evidence for a streptococcal superantigen-driven process in acute guttate psoriasis. J Clin Invest 96: 2106-2112, 1995.

34. Tomi NS, Kränke B and Aberer E: Staphylococcal toxins in patients with psoriasis, atopic dermatitis, and erythroderma, and in healthy control subjects. J Am Acad Dermatol 53: 67-72, 2005. 